\title{
PENAJAMAN CITRA REMOTE SENSING MENGGUNAKAN METODE FILTERING DI AREA PEMBUDIDAYAAN RUMPUT LAUT
}

\author{
Muhammad Sesio Dhia Ramadhan ${ }^{1}$, Nuryuliani ${ }^{2}$, Lulu C Munggaran ${ }^{3}$, Elfitrin Syahrul ${ }^{4}$ \\ Universitas Gunadarma $1,2,3,4$ \\ Jalan Margonda Raya No.100 Pondok Cina, Depok \\ Sur-el : sesioramadhan@gmail.com¹,nryulia@staff.gunadarma.ac.id², \\ lulu@staff.gunadarma.ac.id ${ }^{3,}$ elfitrin@staff.gunadarma.ac.id ${ }^{4}$
}

\begin{abstract}
Indonesia has excellent natural potential for seaweed industry. To help farmers understand the harvest period, an application needs to be built. In this research, a preprocessing application for processing seaweed image processing is taken through remote sensing. Preprocessing is using the Unsharp Mask Filtering and Laplacian Filtering methods. The performace metrics results using the SSIM method show that Laplacian level 2 filtering method gives better result.
\end{abstract}

Keywords: seaweed, Remote sensing, Filtering, Image Enhacement.

\begin{abstract}
Abstrak : Indonesia memiliki potensi alam yang sangat baik untuk Ekspor Industri Rumput Laut. Untuk memudahkan para pembudidaya tani dalam proses panen perlu dibangun suatu aplikasi untuk membantu pembudidaya mengetahui masa panen. Pada penelitian ini dibuat suatu aplikasi Preprocessing pengolahan citra rumput laut yang diambil melalui remote sensing. Preprocessing dilakukan dengan menggunakan metode Unsharp Mask Filtering dan Laplacian Filtering. Hasil ujicoba diukur dengan menggunakan metode SSIM menunjukkan bahwa metode Laplacian Filtering level 2 memberikan hasil yang lebih baik.
\end{abstract}

Kata kunci: Rumput laut, Pencitraan Jarak Jauh, Filtering, Penajaman Citra

\section{PENDAHULUAN}

Indonesia yang memiliki wilayah perairan laut yang luas mencapai 6,4 juta $\mathrm{Km} 2$ dengan garis panjang pantai mencapai $108.000 \mathrm{Km}$. Ada potensi sumber daya kelautan dan perikanan Indonesia sekitar 225 triliun yang berasal dari komoditas unggulan yakni tuna, udang, cakalang, kerapu dan rumput laut. Salah satu komoditas kelautan dan perikanan yang bernilai tinggi adalah rumput laut. Produksi tersebut sebagian besar untuk jenis Euchema spp. dan Gracilaria spp.

Dalam perdagangan internasional, data trademap menunjukkan bahwa Indonesia merupakan salah satu pemain utama dengan volume ekspor pada tahun 2018 sebesar 213 ribu ton (peringkat 1 dengan kontribusi 30\% dari total ekspor dunia). [1] Dengan data ekspor yang tinggi, produksi rumput laut mampu membangkitkan perekonomian masyarakat, terutama masyarakat pesisir. Produksi rumput laut memerlukan biaya operasional atau modal yang ekonomis dan terjangkau, namun dapat memberikan pendapatan yang besar bagi pembudidaya.

Saat ini proses pemanenan rumput laut dapat dilakukan pada umur tanaman 25 - 35 hari jika kondisi perairan memadai dan juga panas matahari mencukupi, namun umumnya produksi 
dapat dipanen pada umur tanaman 45 hari. Sebagian pembudidaya masih belum dapat menentukan kondisi dan estimasi waktu panen rumput laut, karena harus turun langsung ke perairan untuk mengecek rumput laut. Dengan demikian dibutuhkan sesuatu metode yang memudahkan pembudidaya mengetahui kondisi dan estimasi waktu panen dari rumput laut yang ditanam tanpa perlu turun langsung ke perairan. Salah satu caranya ialah dengan membuat sebuah program pemrosesan citra digital untuk area pembudidayaan rumput laut.

Untuk pengambilan citra digital tanaman rumput laut dilakukan menggunakan teknik remote sensing (citra dari satelit atau Unmanned Aerial Vehicle (UAV). Hasil pengambilan gambar perlu dilakukan pre-processing, karena banyak faktor seperti terganggu karena riak di air, warna berkurang, jangkauan cahaya yang terbatas serta pantulan cahaya pada permukaan laut [2]. Tahap pertama untuk mendapatkan hasil identifikasi yang perlu dilakukan adalah menajamkan citra mentah (raw file) untuk memudahkan proses-proses berikutnya yaitu proses segmentasi, ekstraksi ciri, dan terakhir klasifikasi. Aplikasi penajaman citra dibangun menggunakan aplikasi MatLab. Terdapat beberapa pilihan metode penajaman yang bisa digunakan. Dalam penelitian ini untuk penajaman citra rumput laut menggunakan UnSharp Mask dan Laplacian Filter. Penelitian perbaikan citra menggunakan Unsharp masking dilakukan oleh Ahmed Zaafouri, Mounir Syadi dan Farhat Fnaiech untuk perbaikan kontras citra [3]. Teknik filtering menggunakan Laplacian Filter, Homomorphic Filter dilakukan juga oleh
Pushpinder Garg, menunjukan Laplacian Filter memiliki pendekatan hasil yang lebih baik [4]. Ada beberapa metode yang dapat digunakan untuk mengukur performace matrik, seperti Peak Signal to Noise Ratio (PSNR), Normalize Error, Correlation Coefficient dan Structural Similarity (SSIM)[5].

\section{METODOLOGI PENELITIAN}

Pada penelitian ini dibangun aplikasi Penajaman citra digital dengan metode Unsharp Masking dan Laplacian Filter dengan tujuan memberikan detil citra yang lebih baik agar membantu pembudidaya rumput laut dalam tahap awal proses identifikasi perkembangan kondisi dan estimasi waktu panen rumput laut. Untuk membuat program penajaman citra digital ini dibutuhkan program MatLab.

\subsection{Struktur Navigasi}

Aplikasi Penajaman citra digital dengan metode unsharp masking dan laplacian filter ini dirancang dengan sesuai kegunaan dan sederhana agar pengguna dapat memahami disaat menggunakannya. Gambar 1, menunjukkan struktur navigasi dari aplikasi

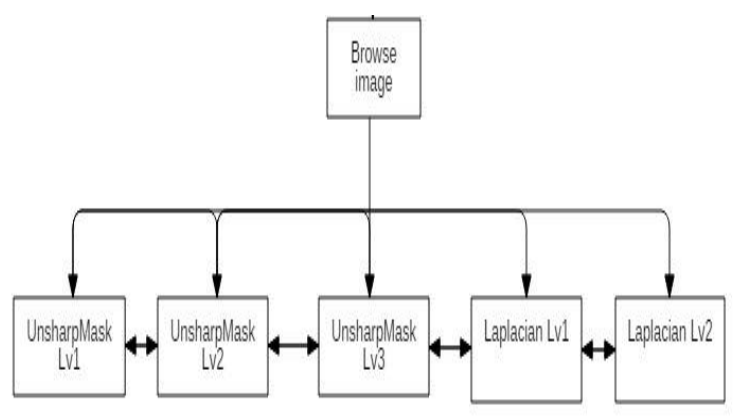

Gambar 1. struktur navigasi dari aplikasi

Penajaman Citra Remote sensing Menggunakan Metode Filtering ... ... 


\subsection{Flowchart}

Aplikasi Penajaman citra digital dengan metode unsharp masking dan laplacian filter ini dirancang dengan sesuai kegunaan dan sederhana agar pengguna dapat memahami disaat menggunakannya. Flowchart program penajaman citra dengan metode Unsharp Masking Filtering dan Laplacian Filter, sebagai pada gambar 2 Dan gambar 3 berikut :

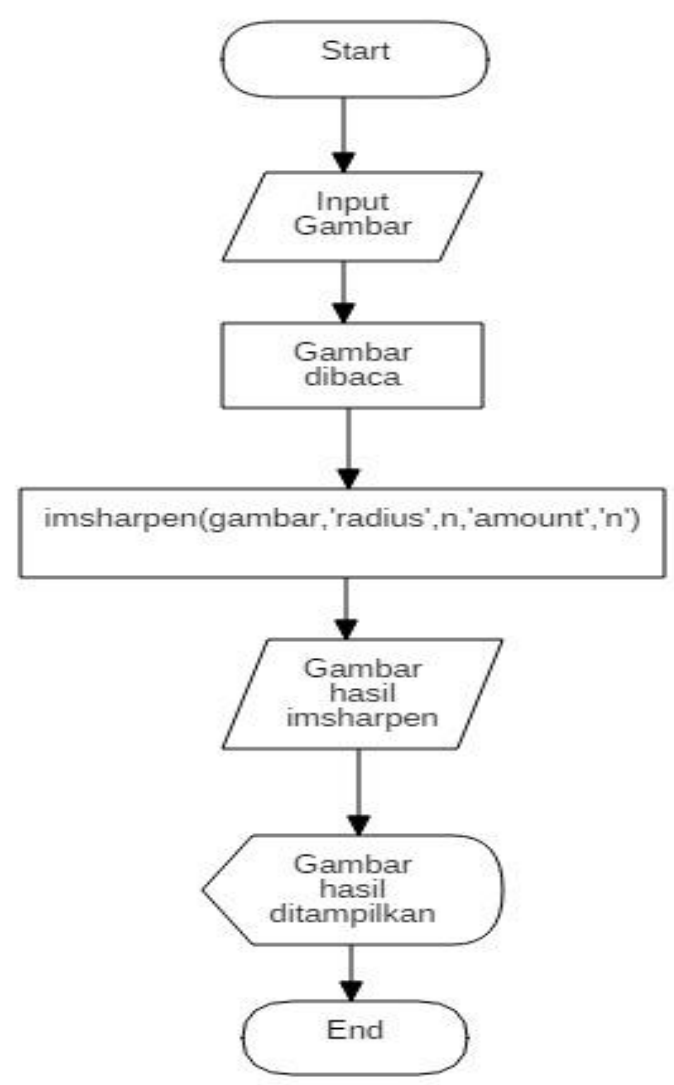

\section{Gambar 2. Flowchart unsharp}

Proses dari flowchart metode unsharp masking dimulai dari memasukan gambar yang akan dilakukan proses penajaman. Gambar tersebut kan dimasukan kedalam fungsi rumus metode unsharp masking. Output dari proses tersebut adalah gambar yang telah ditajamkan. Selanjutnya adalah flowchart untuk Laplacian Filter:

Penajaman Citra Remote sensing Menggunakan Metode Filtering ... ... 


\subsection{Rancangan Tampilan}

Aplikasi Penajaman citra digital dimulai dari pemasukan citra asli kemudian memilih 2 metode yang tersedia dengan intensitas yang dapat dipilih. Gambar hasil dari proses penajaman akan tampil dibagian kiri serta terdapat fitur save guna menyimpan gambar yang telah ditajamkan. Gambar 4 berikut adalah gambar rancangan tampilan aplikasi.

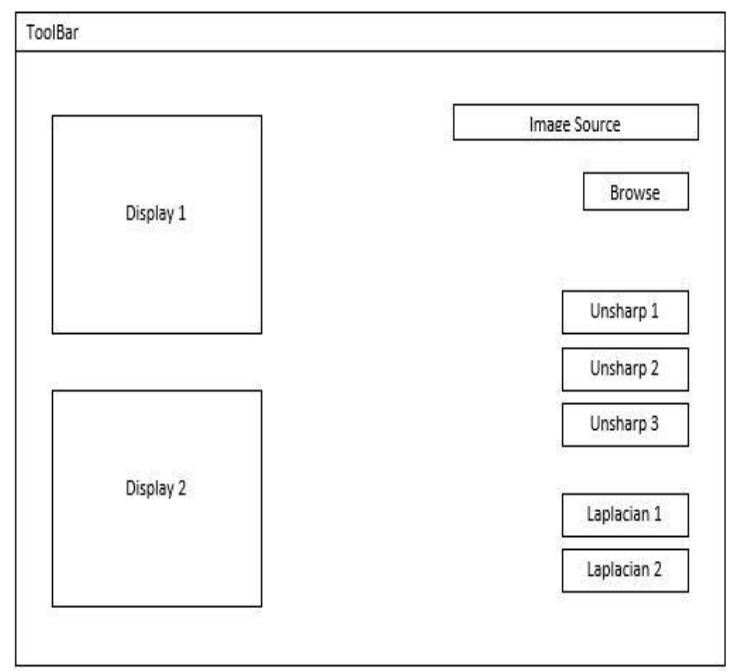

Gambar 4 Rancangan tampilan aplikasi.

Program penajaman citra memiliki rancangan dibagian sisi kiri terdapat 2 display yang merupakan axes yang berfungsi untuk menampilkan gambar asli dan gambar yang telah ditajamkan. Lalu disisi kanan terdapat tombol "browse" berupa toggle button yang fungsinya untuk melakukan input gambar yang akan ditajam kan. Serta pilihan metode Unsharp Masking dan Laplacian Filter yang akan digunakan.

\subsection{Performance Metrics}

Structural Similarity Index Metrics (SSIM) dikenal sebagai kualitas metric yang digunakan untuk mengukur kemiripan diantara 2 buah citra dan dipercaya berkorelasi dengan kualitas persepsi Human Visual System (HVS). Model SSIM dibuat dengan memperhatikan 3 buah faktor yaitu loss of correlation, luminance distortion dan contrast distortion. Persamaan SSIM dapat dilihat pada persamaan 1:

$$
\operatorname{SSIM}(f, g)=l(f, g) c(f, g) s(f, g) \ldots .
$$

Dengan sejumlah faktor lainnya yang dapat dilihat pada persamaan 2

$$
\left\{\begin{array}{l}
l(f, g)=\frac{2 \mu f \mu g+c 1}{\mu f^{2}+\mu g^{2}+c_{1}} \\
c(f, g)=\frac{2 \sigma f \sigma g+c 2}{\sigma f^{2}+\sigma g^{2}+c 2} \ldots \ldots \\
s(f, g)=\frac{2 \sigma_{f g}+c 3}{\sigma_{f} \sigma_{g}+c 3}
\end{array}\right.
$$

SSl (f,g) adalah perbandingan luminansi yang mengukur kemiripan dari nilai luminansi rata-rata 2 citra. Nilai maksimal dari nilai l(f,g) sama dengan 1. Nilai maksimal tersebut akan tercapai bila $\mathrm{miuF}=$ miuG.

$1(f, g)$ adalah perbandingan nilai dari kontras yang mengukur kemiripan nilai standar deviasi citra yaitu sigmaF dan sigmaG, Nilai maksimal dari c(f,g) sama dengan 1. Nilai maksimal tersebut akan tercapai bila sigmaF $=$ sigmaG.

S(f,g) adalah perbandingan struktur yang mengukur koefisien korelasi diantara 2 citra $(f, g)$. Sigma $f$ dan $g$ merupakan nilai kovarian dari f dan g. Jangkauan nilai dari SSIM adalah 0 hingga 1 . Nilai 0 menunjukan bahwa citra sama sekali berbeda serta tidak berkorelasi, sementara nilai 1 menunjukan bahwa citra yang dibandingkan sama persis tanpa perbedaan $\mathrm{f}=\mathrm{g}$, 
sementara c1,c2, dan c3 berfungsi sebagai konstanta agar nilai penyebut tidak sama dengan nol. [6]

\section{HASIL DAN PEMBAHASAN}

Pada tahap ujicoba dilakukan tahapan penajaman citra pada citra rumput laut pada penempatan berbeda. Citra rumput laut di potong dengan konsultasi oleh pihak peneliti dari
Kementerian Kelautan dan Perikanan (KPP) mengenai daerah pemotongan citra yang dianggap sebagai daerah pembudidaya rumput laut. Data juga diambil dari dua jenis data remote Sensing yaitu Data Satelite (Datsat 1 dan Datsat2) dan UAV (DDrone1 dan DDrone2). Hasil uji coba aplikasi dapat dilihat pada Tabel 1 sedangkan Hasil pengukuran kualitas metric dengan menggunakan metode SSIM dapat dilihat pada table 2 .

\section{Tabel 1. Citra Hasil Ujicoba}

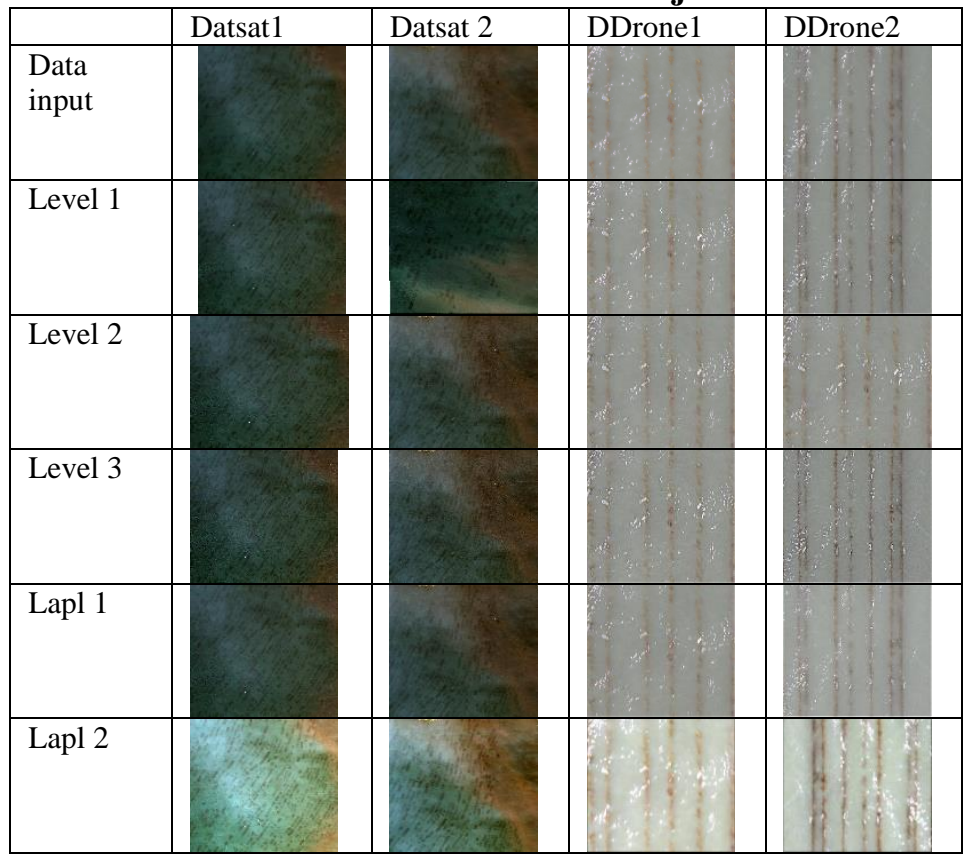

Tabel 2. Hasil Nilai SSIM

\begin{tabular}{llr}
\hline \multicolumn{1}{c}{ Data Input } & \multicolumn{1}{c}{ Metode Filtering } & SSIM value \\
\hline DatSat1 & dat 1 Unsharpmask lv1 & 0.9371 \\
DatSat1 & dat 1 Unsharpmask lv2 & 0.9163 \\
DatSat1 & dat 1 Unsharpmask lv3 & 0.844 \\
DatSat1 & dat 1 Laplacian Filter1 & 0.9371 \\
DatSat1 & dat 1 Laplacian Filter2 & 0.4497 \\
DatSat2 & dat 3 Unsharpmask lv1 \\
DatSat2 & dat 3 Unsharpmask lv2 & 0.9763 \\
DatSat2 & dat 3 Unsharpmask lv3 & 0.9236 \\
DatSat2 & dat 3 Laplacian Filter1 & 0.8558 \\
DatSat2 & dat 3 Laplacian Filter2 & 0.9299
\end{tabular}

Penajaman Citra Remote sensing Menggunakan Metode Filtering ... ... 


$\begin{array}{llr}\text { DDrone1 } & \text { dat 6 Unsharpmask lv1 } & 0.9604 \\ \text { DDrone1 } & \text { dat 6 Unsharpmask lv2 } & 0.9003 \\ \text { DDrone1 } & \text { dat 6 Unsharpmask lv3 } & 0.8321 \\ \text { DDrone1 } & \text { dat 6 Laplacian Filter1 } & 0.8639 \\ \text { DDrone1 } & \text { dat 6 Laplacian Filter2 } & 0.7315 \\ \text { DDrone2 } & \text { dat 7 Unsharpmask lv1 } & 0.953 \\ \text { DDrone2 } & \text { dat 7 Unsharpmask lv2 } & 0.8812 \\ \text { DDrone2 } & \text { dat 7 Unsharpmask lv3 } & 0.8035 \\ \text { DDrone2 } & \text { dat 7 Laplacian Filter1 } & 0.894 \\ \text { DDrone2 } & \text { dat 7 Laplacian Filter2 } & 0.6496\end{array}$

Berdasarkan tabel diatas, dapat terlihat bahwa nilai SSIM terbaik didapat melalui métode Laplacian Filter 2. Nilai terbaik didapat jika mendekati nilai 0 yang berarti makin banyak perubahan yang terjadi pada citra keluaran.

\section{KESIMPULAN}

Penajaman citra rumput laut dengan metode unsharp mask dan laplacian filter telah berhasil dilakukan. Pada teknik Unsahrp Mask penajaman dilakukan dengan melakukan pelapisan gambar asli dengan gambar yang dihaluskan lalu dilakukan perentangan kontras, Sementara pada Laplacian Filter penajaman dilakukan dengan melakukan perubahan dengan mempertimbangkan sejumlah nilai pixel yang berada di sekitarnya. Berdasarkan hasil nilai SSIM, dapat dilihat bahwa metode Laplacian Filter level 2 adalah yang terbaik dibanding yang lain, karena memiliki nilai SSIM yang paling kecil.

Penelitian ini masih belum optimal karena terbatasnya data sample. Data yang diambil melalui Drone masih terkendala dengan adanya pantulan cahaya matahari di permukaan laut.
Penelitian akan lebih optimal jika tersedia data sample yang lebih banyak

\section{UCAPAN TERIMA KASIH}

Ucapan terimakasih kami sampaikan kepada Direktorat Jenderal Penguatan Riset dan Pengembangan - Kementerian Riset, Teknologi dan Pendidikan Tinggi untuk Hibah penelitian Terapan dan Universitas Gunadarma serta Kementerian Kelautan dan Perikanan (KPP).

\section{DAFTAR PUSTAKA}

[1] Arif Wibowo, "Rumput laut komoditas penting yang belum dioptimalkan", Direktorat Pengolahan dan Bina Mutu Ditjen Penguatan Daya Saing Produk Kelautan dan Perikanan -Kementerian Kelautan dan Perikanan, [Online] Available: https://kkp.go.id/djpdspkp/bbp2hp/artikel/1 4127-rumput-laut-komoditas-penting-yangbelum-dioptimalkan [Acessed: 27 September 2019]

[2] Shiwam S Thakare and Amit Sahu, "Comparative Analysis of Various Underwater Image Enhancement Techniques", International Journal of Computer Science and Mobile Computing, IJCSMC, Vol. 3, Issue. 4, ISSN 2320-088X, pp 33-38, 2014. 
[3] Ahmed Zaafouri, Mounir Sayadi dan Farhat Fnaiech, "A Development Unsharp Masking Method for Images Contrast Enhancement", $8^{\text {th }}$ International Multi Conference on System, Signal \& Devices, IEEE, 2011

[4] Pushpinder Garg , H.P.S Kang and Poonam Kumari, "Designing of ESF filter for underwater image enhancement", International Journal of Recent Trends in Engineering \& Research Volume 03, Issue 08, August - 2017 ; ISSN (online): $2455-$ 1457, pp 240-248, 2017

[5] Seema Rajput and S.R. Sularkar, "Comparative Study of Image Enhancement Techniques", International Journal of Computer Science and Mobile Computing, Vol. 2, Issue. 1, ISSN 2320-088X, pp 1121, 2013.

[6] Awaluddin, Moehammad. \& Bambang Darmo. "Penajaman Dan Segmentasi Citra Pada Pengolahan Citra Digital". Teknik. 31(1), ISSN 0852-1697, pp .63-66. 2010. 